\title{
A Técnica do Manejo de Contingência aplicada a adolescentes como forma de melhorar o engajamento no tratamento e diminuir ocorrências relacionadas a comportamentos destrutivos e agressivos, em hospital especializado no tratamento da dependência química.
}

Sabrina Verjas de Almeida, Lucas Cese Marchetti, Maria Cecilia Zarpellom Colognese, Priscila de Freitas Silva e Elizabeth Akemi Nishio

INTRODUÇÃO: Os transtornos psiquiátricos desencadeados pelo uso de substâncias psicoativas atingem milhões de pessoas, sendo que a maioria começam na adolescência, um período marcado por transformações, busca pela identidade pessoal, solidificação dos valores e independência. Uma das técnicas comportamentais, muito utilizada atualmente como tratamento de referência nos EUA e em alguns países europeus para o tratamento de dependentes químicos, é o manejo de contingência em adultos (Villa, 2008). Este trabalho apresenta adaptação desta técnica comportamental para o público adolescente durante a internação para desintoxicação cujos objetivos principais são selecionar e monitorar 0 comportamento desejado.

OBJETIVO: Relatar a experiência da aplicação da técnica de manejo de contingência em adolescentes internados para tratamento de transtornos relacionados ao uso de substâncias.

MÉTODO: Relato de Experiência

DISCUSSÃO: O Projeto Alfa, desenvolvido para adolescentes internados com transtornos desencadeados pelo uso de substâncias psicoativas, recebeu esse nome por fazer parte da primeira fase do tratamento para muitos pacientes. Este projeto utiliza como técnica o manejo de contingência, e esta subdivido da seguinte forma:

Projeto Alfa na Rua: os adolescentes são avaliados semanalmente, onde os comportamentos desejáveis são pontuados. Ao final da semana, são oferecidas atividades externas como forma de incentivo para manter o engajamento no tratamento e o comportamento adequado para aqueles que atingiram a pontuação mínima. As atividades externas visam aumentar o repertório social e apresentar aos adolescentes outras formas de prazer que não estão vinculadas ao uso de substâncias.
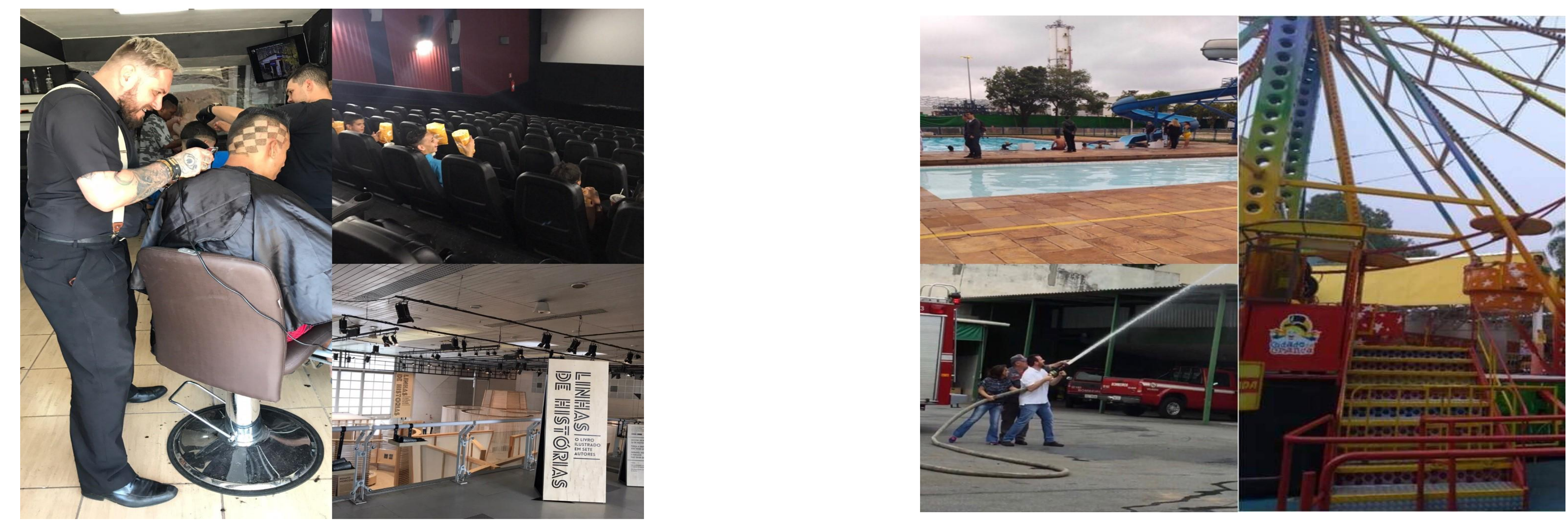

Projeto Alfa Money: este projeto foi idealizado como forma de reforço positivo imediato. $O$ adolescente recebe uma ficha após cada atividade terapêutica que participa e uma vez por semana pode trocar estas fichas por guloseimas no Mercadinho Alfa. Esse reforço incentiva a participação dos pacientes nos grupos terapêuticos, foi possível observar o aumento da aderência e do engajamento no tratamento.

CONCLUSÃO: Concluímos que existem formas inovadoras de envolver o adolescente no tratamento e que os reforços positivos são fundamentais para valorizar e manter os comportamentos desejáveis. Um outro resultado significativo deste projeto foi perceber que os adolescentes também podem se divertir durante a internação, tornando a relação com o tratamento prazerosa, e contribuindo para o aumento do seu repertório de vida social. Outro fator motivador foi observar que durante este um ano de projeto, não tivemos nenhuma ocorrência durante os passeios externos, que era uma preocupação inicial. Há necessidade de se avançar em pesquisas para adolescentes com transtornos relacionados ao uso de substâncias, o manejo de contingência parece ser uma estratégia eficaz, alinhado a necessidade atual de inovar em psiquiatria. 